\title{
ANALISIS KINERJA SENSOR PADA ROBOT PENDETEKSI KOTORAN DEBU DAN AIR
}

\author{
Hermawansa Hermawansa'), Toibah Umi Kalsum ${ }^{2)}$ \\ 1'hermawansa@unived.ac.id, ${ }^{2}$ cicik.umie@gmail.com \\ 1,2Universitas Dehasen Bengkulu
}

\begin{abstract}
Abstrak
Sensor merupakan komponen elektronika yang memiliki kemampuan yang cukup handal dan terdiri dari banyak jenis, seperti sensor ultrasonik, sensor kelembaban, dan sensor debu. Saat ini hampir setiap peralatan elektronik dilengkapi dengan komponen sensor, seperti robot yang dirancang ini, dilengkapi dengan sensor kelembaban dan sensor debu.Tujuan dari penelitian ini adalah untuk mengetahui kinerja dari sensor kelembaban dan sensor debu dalam mendeteksi kotoran lalu sensor mengirim sinyal ke mikrokontroller yaitu Arduino Mega 2560. Dari hasil penelitian kinerja sensor pada robot pendeteksi kotoran debu lantai dan air berbasis Arduino waktu respon sensor jarak mendeteksi penghalang di ruangan senilai 2 detik, waktu respon sensor debu mendeteksi debu lebih lama yaitu 2 menit ini dikarenakan pemasangan sensor debu yang kurang tepat sehingga lambat mendeteksi debu. Sedangkan waktu respon sensor kelembaban dalam mendeteksi air senilai 3 detik. Untuk unjuk kerja robot pada sensor kelembaban membersihkan air di lantai sebanyak $1 \mathrm{ml}$ sebesar 10 sampai dengan 17 detik dan untuk unjuk kerja robot pada sensor kelembaban untuk membersihkan air sebanyak $2 \mathrm{ml}$ sebesar 20 sampai dengan 30 detik.
\end{abstract}

Kata Kunci : Arduino, Sensor Debu, Sensor Kelembaban.

\begin{abstract}
Sensors are electronic components that have capabilities that are quite reliable and consist of many types, such as ultrasonic sensors, humidity sensors, and dust sensors. At present almost every electronic equipment is equipped with sensor components, such as the robot designed, equipped with humidity sensors and dust sensors. The purpose of this study is to determine the performance of the humidity sensor and dust sensor in detecting dirt and the sensor sends a signal to the microcontroller, Arduino Mega 2560. From the results of sensor performance research on Arduino-based floor dust and water dust detector robots the proximity sensor response time detects a barrier in a room worth 2 seconds, the dust sensor response time detects dust that is 2 minutes due to improper installation of dust sensors so that slow detecting dust. While the humidity sensor response time in detecting water is 3 seconds. For the performance of the robot on the humidity sensor clean the water on the floor as much as $1 \mathrm{ml}$ for 10 to 17 seconds and to show the robot's performance on the humidity sensor to clean the water as much as $2 \mathrm{ml}$ for 20 to 30 seconds.
\end{abstract}

Keywords: Arduino, Dust Sensor, Humidity Sensor.

\section{Pendahuluan}

Perkembangan dan pemanfaatan teknologi elektronika diharapkan mampu menciptakan sebuah inovasi perangkat elektronika. Dalam teknologi elektronika dan komputer, efektifitas dan efisiensi selalu menjadi acuan agar setiap langkah dalam penggunaan dan pemanfaatan teknologi diharapkan dapat mencapai hasil yang optimal baik itu dalam kualitas maupun kuantitasnya. Permasalahan yang sering dialami oleh sebagian besar masyarakat khususnya rumah tangga adalah menjaga kebersihan lantai rumah dari kotoran seperti tumpahan air dan debu, sehingga kita harus membersihkan lantai tersebut menggunakan sapu dan kain lap, hal seperti ini memerlukan waktu untuk melakukannya dan terkadang menimbulkan kejenuhan. Dalam hal ini jika kita merancang sebuah alat yang modern yang mana alat tersebut dapat mendeteksi kotoran berupa tumpahan air dan debu menggunakan sensor kelembaban dan sensor debu sehingga alat tersebut dapat otomatis membersihkan lantai secara langsung. Sensor adalah perlatan atau komponen elektronik yang dapat digunakan untuk mendeteksi adanya perubahan suatu lingkungan fisik. Jenis-jenis sensor yang digunakan pada penelitian ini adalah:

a. Sensor debu adalah sensor oleh penginderaan optik system, sensor ini mendeteksi cahaya yang dipantulkan debu di udara [1]. 
b. Sensor kelembaan adalah suatu alat ukur yang digunakan untuk membantu dalam proses pengukuran tingkat kelembaban uap air yang terkandung dalam udara 2].

c. Sensor ultrasonic adalah sebuah sensor yang mengubah besaran fisis (bunyi) menjadi besaran listrik [3]. Pada sensor ini gelombang ultrasonic dibangkitkan melalui sebuah benda yang disebut piezoelektrik.

d. Sensor posisi, merupakan sensor atau saklar yang bekerja berdasarkan jarak objek terhadap sensor yang dapat mendeteksi adanya target jenis logam dengan tanpa adanya kontak fisik [4].

Tujuan dari penelitian ini adalah untuk mengetahui kinerja dari sensor kelembaban dan sensor debu dalam mendeteksi kotoran lalu sensor mengirim sinyal ke mikrokontroller yaitu Arduino. Arduino adalah papan mikrokontroler yang berbasis Atmega 328p yang mempunyai 14 digital input/output [5]. Arduino yang digunakan dalam penelitian ini adalah Arduino Mega 2560, memiliki kelebihan yang mirip dengan Arduino Uno. Arduino Mega 2560 adalah versi terbaru yang menggantikan versi Arduino Mega, tetapi Arduino Mega menggunakan Chip yang lebih tinggi yaitu ATMEGA 2560 dan tentu saja untuk Pin I/O Digital dan pin input analognya lebih banyak dari Arduino Uno.

Arduino Mega 2560 memiliki 54 pin digital input/output, dimana 15 pin dapat digunakan sebagai output PWM, 16 pin sebagai input analog, dan 4 pin sebagai UART (port serial hardware), $16 \mathrm{MHz}$ kristal osilator, koneksi USB, jack power, header ICSP, dan tombol reset. Ini semua yang diperlukan untuk mendukung mikrokontroler. Penggunaan arduino mega ini cukup dengan menghubungkannya ke komputer melalui kabel USB atau power dihubungkan dengan adaptor AC-DC atau baterai untuk mulai mengaktifkannya. Arduino Mega 2560 kompatibel dengan sebagian besar shield yang dirancang untuk Arduino Duemilanove atau Arduino Diecimila. Berdasarkan uraian di atas, maka penulis tertarik untuk mengangkat judul yaitu : "Analisa Kinerja Sensor pada Pendeteksi Kotoran Debu dan Air". Dalam penelitian ini, yang ingin dilihat adalah kemampuan kinerja dust sensor dan sensor kelembabab dalam mendeteksi keberadaan debu dan cairan yang menempel di lantai serta pergerakan robot dalam menentukan arah. Permasalahan yang akan dibahas oleh peneliti yaitu bagaimana kinerja sensor-sensor pada robot tersebut. Adapun batasan masalah yang penulis angkat yaitu kecepatan dan ketepatan sensor robot dalam mendeteksi debu pada lantai dan pergerakan robot dalam menentukan arah.Tujuan utama dalam penelitian yang akan dicapai dari penulisan adalah terciptanya sebuah robot yang dapat bergerak dan mendeteksi adanya debu atau kotoran yang menempel pada lantai.

\section{Metode}

\subsection{Metode Penelitian}

Metode penelitian yang digunakan adalah metode eksperimen, penelitian yang dilakukan akan terfokus pada sensor jarak ultrasonik, sensor posisi dengan mikrokontroler Arduino Atmega 2560. metode penelitian yang digunakan untuk menghasilkan produk tertentu, dan menguji keefektifan produk tersebut.

\subsection{Hardware dan Software}

Adapun perangkat keras (hardware) dan perangkat lunak (software) yang digunakan dalam membuat Robot pendeteksi kotoran dan air dilantai berbasis Arduino ini adalah sebagai berikut :

1. Perangkat keras (hardware) yang digunakan dalam penelitian ini, dapat dilihat pada tabel 1.

Tabel 1. Spesifikasi perangkat keras

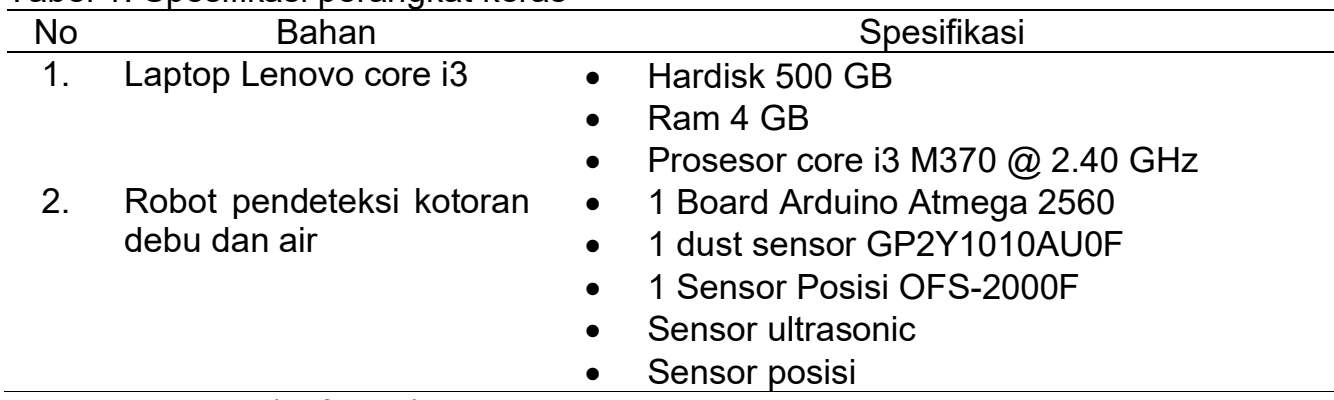

2. Perangkat lunak (software) yang digunakan dalam penelitian ini adalah Arduino IDE 
ILKOM Jurnal Ilmiah Volume 11 Nomor 1 April 2019

Terakreditasi peringkat 3 SK. No. 28/E/KPT/2019

\subsection{Metode Perancangan Sistem}

\subsubsection{Blok Diagram Global}

Diagram blok yang digunakan dalam penelitian ini adalah sebagai berikut :

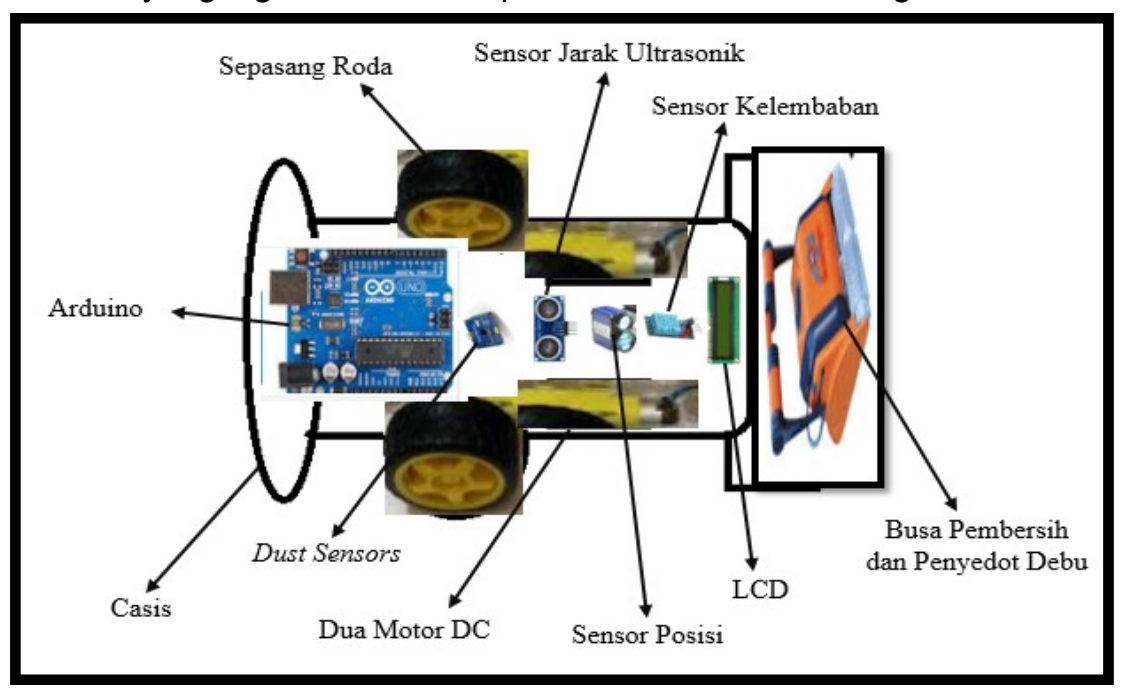

Gambar 1. Blok Diagram Global

Pada gambar 1. Blok diagram global di atas, dengan menggunakan aplikasi Boarduino yang di upload dari komputer pada Arduino Atmega 2560 yang terhubung ke sensor kelembaban dan sensor debu, kemudian arduino Atmega 2560 akan memberikan perintah pada sensor kelembaban dan sensor debu untuk mendeteksi adanya air dan debu di lantai untuk dibersihkan menggunakan busa pembersih penyedot debu.

\subsubsection{Blok Diagram Rangkaian Alat}

Diagram blok rangkaian robot pembersih lantai terdiri dari Arduino Atmega 2560, Icd, sensor jarak ultrasonik, sensor posisi, sepasang motor dc, dan busa pembersih. Adapun diagram blok rangkaian alat dalam penelitian ini ditunjukan pada gambar 2.

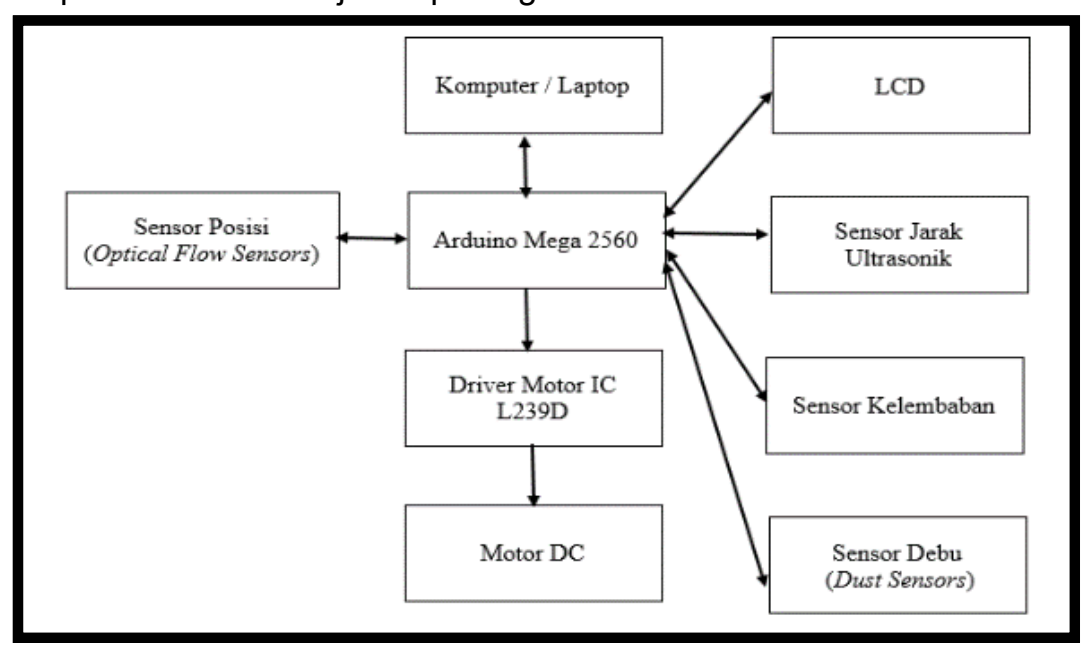

Keterangan gambar :

Gambar 2. Blok Digram Rangkaian Alat

1. Komputer atau laptop yang dihubungkan dengan Arduino Atmega 2560 digunakan sebagai perancang program untuk Robot Pembersih Lantai Berbasis Arduino Menggunakan Sensor Jarak Ultrasonik Dan Sensor Posisi.

2. Arduino Atmega 2560 berfungsi untuk mengolah data berupa program yang di upload dari komputer dengan menggunakan serial USB. Arduino Atmega 2560 ini dihubungkan dengan

DOI: http://dx.doi.org/10.33096/ilkom.v11i1.405.53-58

ILKOM Jurnal IImiah work is licensed under a CCA-SA 4.0 International License. | 55 
ILKOM Jurnal Ilmiah Volume 11 Nomor 1 April 2019

Terakreditasi peringkat 3 SK. No. 28/E/KPT/2019

sensor ultrasonik untuk mendeteksi objek, sensor posisi untuk mendeteksi ruangan, sensor kelembaban untuk mendeteksi adanya air, sensor debu untuk mendeteksi adanya debu, LCD untuk menampilkan output yang dihasilkan oleh sensor-sensor tersebut dan driver Motor IC L293D digunakan untuk membuat driver H-bridge untuk 2 buah motor DC.

\subsubsection{Desain Rangkaian Alat}

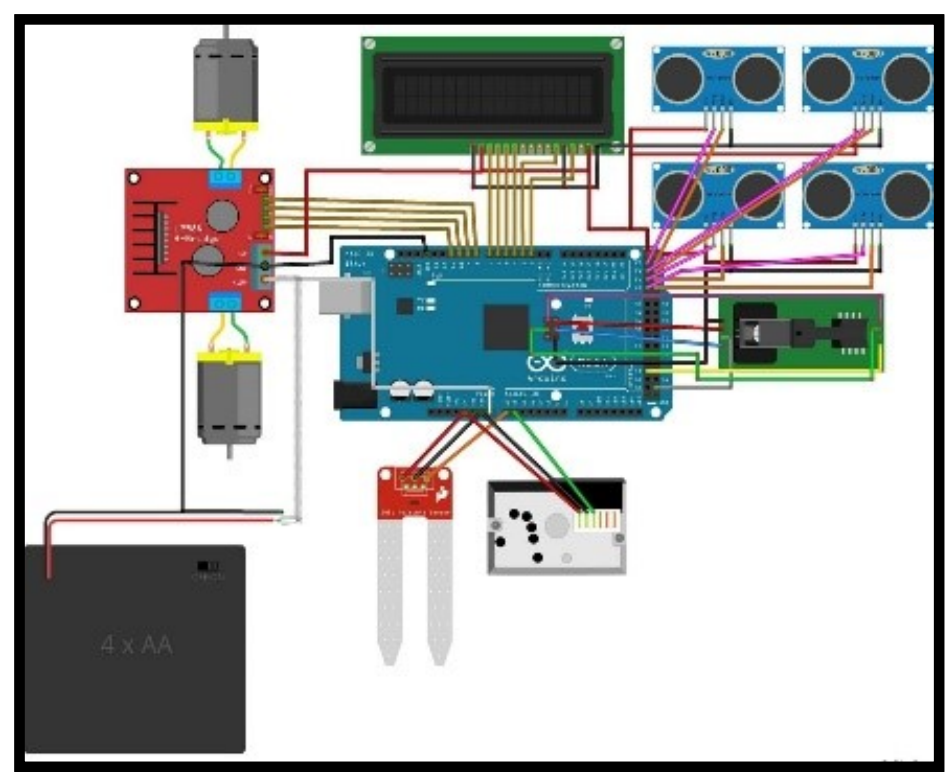

Gambar 3. Desain Rangkaian Alat

Gambar 3 merupakan desain rangkaian alat. Adapun untuk mendapatkan desain rangkaian Robot pendeteksi kotoran debu dan air pada lantai. Arduino Atmega 2560 dihubungkan ke sensor Ultrasonik untuk mendeteksi objek di lantai ruangan, sensor kelembaban untuk mendeteksi air, sensor debu (dust sensors) untuk mendeteksi debu di lantai agar dapat langsung dibersihkan oleh penyedot robot dan Lcd berfungsi untuk menapilkan suatu karakter tulisan dan gambar di layar. Arduino Mega 2560 memiliki 54 pin digital input/output, dimana 15 pin dapat digunakan sebagai output PWM, 16 pin sebagai input analog, dan 4 pin sebagai UART (port serial hardware), $16 \mathrm{MHz}$ kristal osilator, koneksi USB, jack power, header ICSP, dan tombol reset.

\subsubsection{Cara Kerja Sistem}

Cara kerja robot pembersih lantai berbasis arduino menggunakan sensor jarak ultrasonik, sensor posisi (optical flow sensors), sensor kelembaban dan sensor debu (dust sensors) yaitu ketika sensor posisi (optical flow sensors) mendeteksi ruangan lalu sensor jarak mendeteksi objek yang ada di lantai ruangan setelah itu jika sensor kelembaban mendeteksi kotoran berupa air maka sensor kelembaban mengirim sinyal ke arduino untuk memerintahkan busa pembersi (kanebo) membersihkan air tersebut begitupun selanjutnya robot ini dilengkapi dengan sensor debu (dust sensors) yang mana jika sensor debu (dust sensors) mendeteksi adanya debu dilantai maka sensor sensor debu (dust sensors) mengirim sinyal ke arduino untuk memerintahkan penyedot untuk menyedot debu. Keluaran dari kerja robot pembersihan dapat ditampilkan oleh LCD.

\section{Hasil dan Pembahasan}

Hasil analsisis kinerja sensor pada robot pembersih lantai berbasis Arduino, pada robot ini menggunakan Arduino Atmega 2560 berfungsi untuk mengolah data berupa program yang di upload dari komputer, sensor posisi (optical flow sensors) berfungsi untuk mendeteksi ruangan, sensor ultrasonik berfungsi untuk mendeteksi objek yang ada di lantai ruangan, sensor kelembaban berfungsi untuk mendeteksi air di lantai, sensor debu (dust sensors) berfungsi untuk mendeteksi debu di lantaidan Motor DC berfungsi sebagai penggerak badan Robot. Dalam penelitian ini, penulis mendapatkan hasil dapat dilihat pada gambar 4. 
ILKOM Jurnal Ilmiah Volume 11 Nomor 1 April 2019

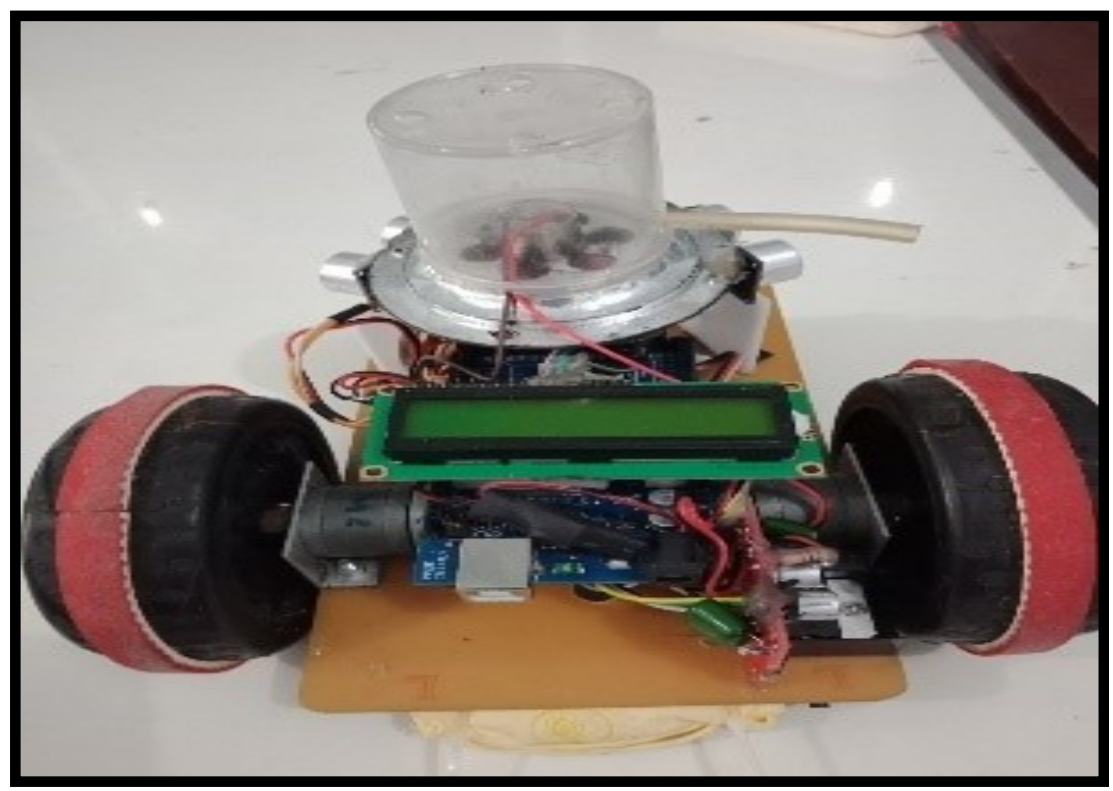

Gambar 4. Hasil Robot Pembersih Lantai

Ketika sensor posisi (optical flow sensors) mendeteksi ruangan lalu sensor jarak mendeteksi objek yang ada di lantai ruangan setelah itu jika sensor kelembaban mendeteksi kotoran berupa air maka sensor kelembaban mengirim sinyal ke arduino untuk memerintahkan busa pembersi (kanebo) membersihkan air tersebut begitupun selanjutnya robot ini dilengkapi dengan sensor debu (dust sensors) yang mana jika sensor debu (dust sensors) mendeteksi adanya debu dilantai maka sensor sensor debu (dust sensors) mengirim sinyal ke arduino untuk memerintahkan penyedot untuk menyedot debu. Keluaran dari kerja robot pembersihan dapat ditampilkan oleh LCD.

Setelah semua modul terhubung ke Arduino Atmega 2560, berikutnya dilakukan pengujian. Adapun hasil pengujian yang dilakukan seperti pada tabel 2 berikut :

Tabel 2. Hasil Pengujian Robot Pembersih Lantai Berbasis Arduino

\begin{tabular}{|c|c|c|c|}
\hline No. & Kriteria Pengujian & Hasil (Waktu ) & Keterangan \\
\hline 1 & $\begin{array}{l}\text { Kecepatan respon sensor } \\
\text { ultrasonik mendeteksi } \\
\text { penghalang di lantai } \\
\text { ruangan. }\end{array}$ & 2 detik & Sensor dapat mendeteksi \\
\hline 2 & $\begin{array}{l}\text { Kecepatan respon sensor } \\
\text { debu dalam mendeteksi } \\
\text { debu }\end{array}$ & 2 menit & Sensor dapat mendeteksi \\
\hline 3 & $\begin{array}{l}\text { Kecepatan respon sensor } \\
\text { kelembaban } \\
\text { mendeteksi air pada lantai }\end{array}$ & 3 detik & Sensor dapat mendeteksi \\
\hline 4 & $\begin{array}{l}\text { Unjuk Kerja Robot dalam } \\
\text { membersihkan lantai dengan } \\
\text { Air sebanyak } 1 \mathrm{ml}\end{array}$ & $10-17$ detik & $\begin{array}{l}\text { Robot dapat } \\
\text { membersihkan air di lantai } \\
\text { dengan waktu } 10 \text { detik s.d } \\
17 \text { detik. }\end{array}$ \\
\hline 5 & $\begin{array}{l}\text { Unjuk Kerja Robot dalam } \\
\text { Mengepel lantai dengan Air } \\
\text { sebanyak } 2 \mathrm{ml}\end{array}$ & 20 - 30 detik & $\begin{array}{l}\text { Robot dapat } \\
\text { membersihkan air di lantai } \\
\text { dengan waktu } 20 \text { detik s.d } \\
30 \text { detik. }\end{array}$ \\
\hline
\end{tabular}


Dari tabel hasil pengujian di atas, dapat disimpulkan bahwa robot pembersih lantai berbasis arduino dengan kriteria pengujian kecepatan respon sensor. Sensor ultrasonik dapat mendeteksi penghalang di lantai ruangan dengan waktu respon sebesar 2 detik, dan kecepatan respon sensor debu dalam untuk mendeteksi adanya kotoran debu di lantai sebesar 2 menit, sedangkan unjuk kerja sensor debu yang kurang mendeteksi debu dikarenakan peletakan sensor debunya terlalu tinggi sehingga unjuk kerja robot pembersih jika mendeteksi debu menjadi berkurang. Serta hasil kecepatan respon sensor kelembaban dalam mendeteksi air sebesar 3 detik dan unjuk kerja sensor kelembaban yang mana langsung dapat mendeteksi air dikarenakan pemasangan sensor kelembaban yang tepat posisinya pada robot.

\section{Kesimpulan}

1. Waktu respon sensor jarak (ultrasonik) dalam mendeteksi penghalang sebesar 2 detik, sensor debu dalam mendeteksi adanya kotoran debu sebesar 2 menit dan sensor kelembaban dalam mendeteksi air sebesar 3 detik.

2. Sedangkan hasil unjuk kerja sensor debu yang kurang mendeteksi debu dikarenakan peletakan sensor debunya terlalu tinggi sehingga unjuk kerja robot pembersih jika mendeteksi debu menjadi berkurang sedangkan unjuk kerja sensor kelembaban yang mana langsung dapat mendeteksi air dikarenakan pemasangan sensor kelembaban yang tepat posisinya pada robot.

3. Untuk unjuk kerja robot pembersih mengepel lantai air sebanyak $1 \mathrm{ml}$ sebesar $10 \mathrm{~s} . \mathrm{d} 17$ detik dan untuk unjuk kerja robot pembersih mengepel lantai air sebanyak $1 \mathrm{ml}$ sebesar 20 s.d 30 detik. Jadi dapat disimpulkan presentase tingkat pembersihannya sebesar $70 \%$.

4. Agar robot ini dapat dikembangkan kembali sehingga memiliki kemampuan yang lebih dari robot pembersih lantai bisa dilengkapi dengan menambahkan ruang gerak robot yang lebih luas.

5. Pemasangan sensor debu harus di letakkan dengan benar pada robot. Selain itu kelemahan robot ini ada tingkat pembersihan lantai yang kurang optimal dikarenakan busa pembersih yang ukurannya terlalu kecil.

\section{Terima Kasih}

Penulis mengucapkan terima kasih kepada Universitas Dehasen Bengkulu yang telah memberikan dukungan finansial terhadap penelitian ini. Terima kasih kepada rekan-rekan dosen yang telah memberikan masukan dan dukungan dalam menyelesaikan tulisan ini.

\section{Daftar Pustaka}

[1] Sahal Muhammad and Azizahwati. 2014. Pembuatan Media Rangkaian Dasar Mosfet Sebagai Pengendalii Motor. Perpusatakanan Universitas Riau. 10-17 halaman.

[2] Akbar Ali Akmal Muhammad. 2016. Instrumentasi Industri Sensor Kelembaban. Program Studi Teknik Elektro. Fakultas Sains Dan Teknologi. Universitas Islam Negeri Suska Riau. 1-12 halaman .

[3] Fandhi Nugraha K. 2016, Sensor Utrasonik HC-SR 04. Universitas Hasanuddin. Makasar. 1-12 halaman.

[4] Lamsani Misa. 2015. Buku Elektronika Lanjut. Universitas Gunadarma. Jakarta, 1-170 halaman.

[5] Anwar Yogie et al., 2015. Prototype penggerak pintu pagar otomatis berbasis arduino uno Atmega 328p dengan sensor sidik jari. Jurnal Rekayasa dan teknologi elektro. Vol. 9, No.1, 3041 halaman. 